\title{
Erratum to: Internalization of Appearance Ideals and Cosmetic Surgery Attitudes: A Test of the Tripartite Influence Model of Body Image
}

Jessie E. Menzel • Steffanie L. Sperry • Brent Small •

J. Kevin Thompson • David B. Sarwer • Thomas F. Cash

Published online: 28 July 2011

(C) Springer Science+Business Media, LLC 2011

Erratum to: Sex Roles

DOI 10.1007/s11199-011-9983-7

Due to an error in production, the value for the pathway between body satisfaction and cosmetic surgery attitudes for men was mislabeled in Fig. $2 \mathrm{~b}$. The value should be $-.28 *$.

The online version of the original article can be found at http://dx.doi. org/10.1007/s11199-011-9983-7.

J. E. Menzel $\cdot$ S. L. Sperry • B. Small $\cdot$ J. K. Thompson $(\bowtie)$

Department of Psychology, University of South Florida,

Tampa, FL 33620, USA

e-mail: Thompsonjk2003@yahoo.com

D. B. Sarwer

University of Pennsylvania School of Medicine,

Philadelphia, PA, USA

T. F. Cash

Old Dominion University,

Norfolk, VA, USA 